\title{
Combinatorial surface coating and greatly-improved soft magnetic performance of $\mathrm{Fe} / \mathrm{Fe}_{3} \mathrm{O}_{4} /$ resin composites
}

\author{
Bingyang Meng ${ }^{\mathrm{a}}$, Bai Yang ${ }^{\mathrm{a}, *}$, Xixiang Zhang ${ }^{\mathrm{b}}$, Bohui Zhou ${ }^{\mathrm{a}}$, Xiaopan $\mathrm{Li}^{\mathrm{a}}$, Ronghai Yu ${ }^{\mathrm{a},{ }^{, * *}}$ \\ ${ }^{a}$ Key Laboratory of Aerospace Advanced Materials and Performance, Ministry of Education, School of Materials Science and Engineering, Beihang University, Beijing, \\ 100191, China \\ ${ }^{\mathrm{b}}$ Nanofab, Imaging \& Characterization Core Lab, King Abdullah University of Science and Technology, Thuwal, 23955-6900, Saudi Arabia
}

\section{H I G H L I G H T S}

- $\mathrm{Fe} / \mathrm{Fe}_{3} \mathrm{O}_{4} /$ resin composites were fabricated by combinatorial coating methods.

- $\mathrm{Fe}_{3} \mathrm{O}_{4}$ nanolayers can reserve high saturation magnetization for the composites.

- Uniform resin coating promoted the reinforced structures of the composites.

- High density and high TRS values were achieved in the compacted composites.

- Good soft magnetic properties were obtained in the $\mathrm{Fe} / \mathrm{Fe}_{3} \mathrm{O}_{4} /$ resin composites.

\section{A R T I C L E I N F O}

\section{Keywords:}

$\mathrm{Fe} / \mathrm{Fe}_{3} \mathrm{O}_{4} /$ Resin SMCs

Controlled oxidation

Physical coating

High transverse rupture strength

Greatly enhanced soft magnetic performance

\section{G R A P H I C A L A B S T R A C T}
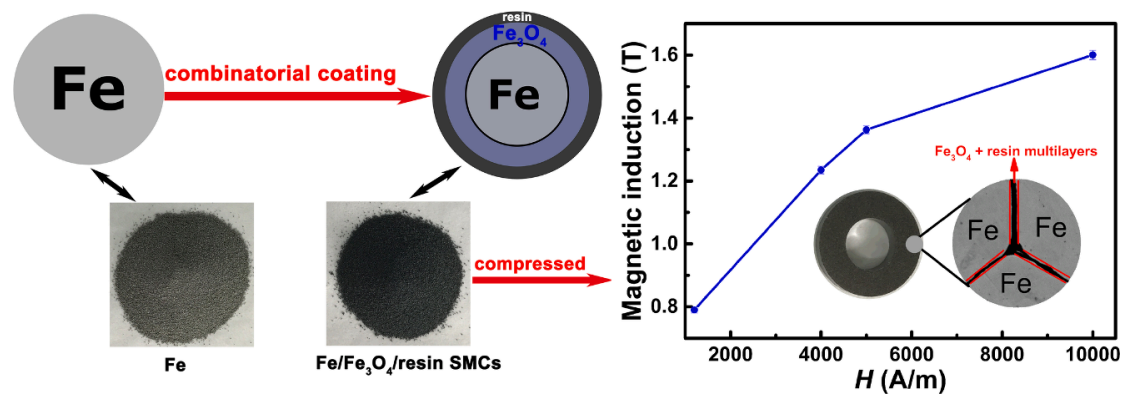

\begin{abstract}
A B S T R A C T
Structure-reinforced $\mathrm{Fe} / \mathrm{Fe}_{3} \mathrm{O}_{4} /$ resin soft magnetic composites (SMCs) have been fabricated through coating micron-sized Fe powders with high-purity $\mathrm{Fe}_{3} \mathrm{O}_{4}$ nanolayers and silicon resin films by combinatorial controlled oxidation and physical coating method. High magnetization $M_{s}$ of $201 \mathrm{~A} \mathrm{~m}^{2} \mathrm{~kg}^{-1}$ can be reserved in the Fe/ $\mathrm{Fe}_{3} \mathrm{O}_{4}$ /resin SMCs due to high-purity ferrimagnetic $\mathrm{Fe}_{3} \mathrm{O}_{4}$ shells and low-content resin layers. The smooth $\mathrm{Fe} /$ $\mathrm{Fe}_{3} \mathrm{O}_{4}$ interfaces and uniform silicone resin coating layers in the $\mathrm{Fe} / \mathrm{Fe}_{3} \mathrm{O}_{4} /$ resin SMCs also lead to their low coercivity of 11.4 Oe and high compressed density of $7.50 \mathrm{~g} / \mathrm{cm}^{3}$. For traditional metal-based SMCs fabricated by various common coating methods, their reduced core loss is usually achieved but accompanying with low magnetic induction and poor mechanical properties. In this work, high transverse rupture strength value of 92 $\mathrm{MPa}$ and greatly enhanced soft magnetic performance with both decreased core loss in accompany with high magnetic inductions are achieved for the fully densified $\mathrm{Fe} / \mathrm{Fe}_{3} \mathrm{O}_{4} /$ resin SMCs due to their well-structured composite interfaces, which promise their great latent applications for high-power and low-loss magnetic components.
\end{abstract}

\footnotetext{
* Corresponding author.

$* *$ Corresponding author.

E-mail addresses: byang@buaa.edu.cn (B. Yang), rhyu@buaa.edu.cn (R. Yu).
} 


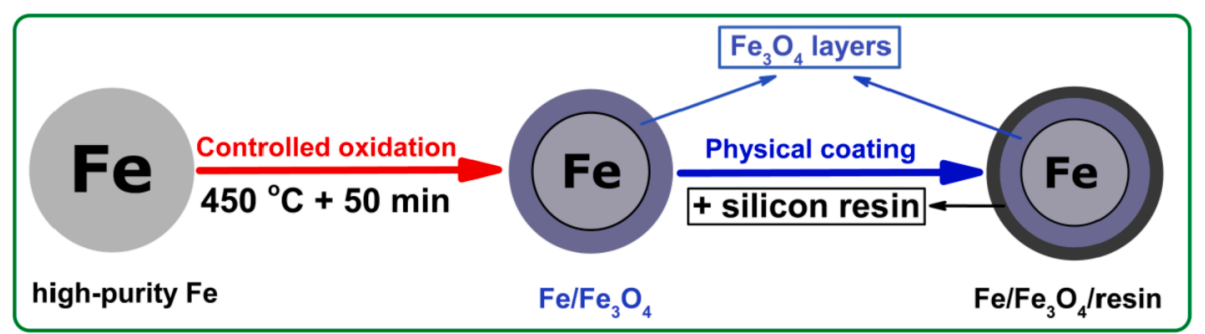

Fig. 1. The schematic illustration of preparation for $\mathrm{Fe} / \mathrm{Fe}_{3} \mathrm{O}_{4} / \mathrm{resin}$ composites.

\section{Introduction}

High-performance metal-based soft magnetic composites (SMCs) have consistently received much research interests due to the improved overall properties containing decreased core loss, desirable frequencydependent magnetic performance and good processibility for the composites, which can be used for various high-power or low-loss magnetic components with complex shapes [1-4]. In the past few decades, many metal-based SMCs with core-shell structure have been prepared by coating $\mathrm{Fe}$ or Fe-based alloy particles (FeSi, FeCo, FeSiAl, FeNi and amorphous alloys) as the cores with high-resistivity or electrical insulating layers (epoxy resin, $\mathrm{SiO}_{2}, \mathrm{MgO}, \mathrm{NiZnFe}_{2} \mathrm{O}_{4}, \mathrm{Al}_{2} \mathrm{O}_{3}, \mathrm{TiO}_{2}, \mathrm{ZrO}_{2}$ and $\mathrm{SiO}_{2}-\mathrm{Na}_{2} \mathrm{O}-\mathrm{CaO}$ silicate) as the shells by several chemical or physical methods [5-14]. Commonly, these metal-based SMCs can exhibit improved soft magnetic performance such as reduced core loss, improved frequency magnetic performance and three-dimensional isotropic ferromagnetic behavior due to the suitable coating layers. Especially, the $\mathrm{SiO}_{2}$-coated iron submicrometer laminates show decreased core loss accompanying with greatly-improved high-frequency magnetic performance under a maximum applied frequency reaching $50 \mathrm{MHz}$ [15]. However, decreased core loss is often achieved in these conventional core-shell structured SMCs by seriously decreasing their magnetic inductions because of low density of nonmagnetic coating layers [16-18]. Moreover, the most current researches on SMCs have always focused on the improvement of their soft magnetic properties, but very few studies have involved their mechanical properties. As is known, the bulk SMCs are generally obtained by directly compressing the initially prepared metal-based composite particles at room temperature but not by sintering at high temperature due to their poor heat resistance [19-21]. Thus, low interfacial bonding strength would occur between the cores and the coating layers, and deformation inconsistency also exists between the two parts in metal-based composite particles, both of which can lead to their poor compactness so as to result in low density and low transverse rupture strength (TRS) in bulk SMCs [22,23]. Most of recent research for metal-based SMCs has been still focused on the enhancement of their magnetic properties by decreasing their core loss while maintaining their high saturation magnetization, which can be successfully realized by optimizing various metal-based core-shell interface structures fabricated through various coating methods [24-28]. However, the mechanical properties for full-density metal-based SMCs also need to be improved. Thus, it is necessary to explore suitable preparation method to fabricate high-performance SMCs with the ideal composite structures, which can result in their both good magnetic and mechanical properties to accord the requirement for practical applications.

In this work, the $\mathrm{Fe} / \mathrm{Fe}_{3} \mathrm{O}_{4}$ core-shell structures have been firstly fabricated through coating micron-sized Fe powders with high-purity $\mathrm{Fe}_{3} \mathrm{O}_{4}$ nanolayers by controlled oxidation. The reduced core loss along with high magnetic inductions can be obtained in the $\mathrm{Fe} / \mathrm{Fe}_{3} \mathrm{O}_{4} \mathrm{SMCs}$ due to the ferrimagnetic $\mathrm{Fe}_{3} \mathrm{O}_{4}$ nanolayers with relatively high electric resistivity. Then, suitable amount of silicone resin is coated on the initially oxidized Fe-based composites to form new-type $\mathrm{Fe} / \mathrm{Fe}_{3} \mathrm{O}_{4} /$ resin SMCs, which can exhibit high compaction density, greatly-improved soft magnetic performance and high TRS value due to the combinatorial
$\mathrm{Fe}_{3} \mathrm{O}_{4}$ and resin coatings, which promote their practical applications for many metal-based magnetic devices including particularly the complexshaped motors or generators. The interfacial structures accompanying with their influences on magnetic and mechanical properties of the $\mathrm{Fe} /$ $\mathrm{Fe}_{3} \mathrm{O}_{4} /$ resin SMCs have been also investigated systematically.

\section{Experimental}

\subsection{Fabrication of $\mathrm{Fe} / \mathrm{Fe}_{3} \mathrm{O}_{4} /$ resin $\mathrm{SMCs}$}

The commercial high-purity Fe powders with average particle size of approximately $170 \mu \mathrm{m}$ (bought from Titd Metal materials Co., Ltd, China) used as the raw materials. The commercial silicon resin solution containing $50 \mathrm{wt} \%$ solid silicone resin dissolved in toluene solvent was supplied by Shin-Etsu Chemical Co., Ltd. Japan.

The $\mathrm{Fe} / \mathrm{Fe}_{3} \mathrm{O}_{4}$ core-shell composites were firstly prepared by properly oxidizing the micron-sized $\mathrm{Fe}$ powders under an appropriate controllable oxidation condition, and then the $\mathrm{Fe} / \mathrm{Fe}_{3} \mathrm{O}_{4} /$ resin SMCs were obtained by coating the properly oxidized Fe particles with suitable amount of silicon resin through a physical coating method. Fig. 1 displays the schematic preparation process for $\mathrm{Fe} / \mathrm{Fe}_{3} \mathrm{O}_{4} /$ resin SMCs. The main reaction is illustrated as followed:

$3 \mathrm{Fe}+2 \mathrm{O}_{2} \rightarrow \mathrm{Fe}_{3} \mathrm{O}_{4}$

Firstly, high-purity $\mathrm{Fe}_{3} \mathrm{O}_{4}$ shells with $60-80 \mathrm{~nm}$ thickness are in situ formed on the surfaces of unoxidized Fe parts to generate $\mathrm{Fe} / \mathrm{Fe}_{3} \mathrm{O}_{4}$ coreshell structured composites under the controlled oxidation based on formula (1). The detailed controlled oxidation process for metal particles can refer to our previous work in Ref. [9]. In this work, only surface ferrimagnetic $\mathrm{Fe}_{3} \mathrm{O}_{4}$ phase excluding the other Fe oxides such as $\mathrm{FeO}$, $\mathrm{Fe}_{2} \mathrm{O}_{3}$ and their mixtures is expected to form the micron-nano $\mathrm{Fe} / \mathrm{Fe}_{3} \mathrm{O}_{4}$ composites with core-shell structure, which can result in their increased electrical resistivity along with good intrinsic magnetism and thus to improve the soft magnetic properties of the composites. In a typical controlled oxidation procedure, a certain amount of high-purity micron-sized Fe particles were loaded into a tubular furnace under a controlled atmosphere, and then were quickly heated at a temperature rate with $8{ }^{\circ} \mathrm{C} / \mathrm{min}$ from $25^{\circ} \mathrm{C}$ to $450{ }^{\circ} \mathrm{C}$ at a vacuum of $1.0 \times 10^{-3} \mathrm{~Pa}$. When the temperature approached $450{ }^{\circ} \mathrm{C}$, the gas mixture containing high purity oxygen and argon gas with their volume ratios fixed at $2: 8$ was quickly pumped into the furnace, which was then sealed until the pressure for mixed gas approached $1 \mathrm{~atm}$. Afterwards, the micron-sized Fe powders were heated continuously beyond the mixed oxygen-argon atmosphere at $450{ }^{\circ} \mathrm{C}$ for $50 \mathrm{~min}$. The $\mathrm{Fe} / \mathrm{Fe}_{3} \mathrm{O}_{4}$ composites were obtained when the continuously heated Fe particles were naturally cooled from $450{ }^{\circ} \mathrm{C}$ to room temperature. Secondly, the above properly oxidized Fe particles were put into a silicon resin solution diluted with certain amount of acetone and then quickly stirred until all the solvents in the solution completely evaporate to obtain the sample with wet surface. The $\mathrm{Fe} / \mathrm{Fe}_{3} \mathrm{O}_{4} /$ resin SMCs as the end product can be obtained by naturally drying the wet sample in the air for $24 \mathrm{~h}$. The solid silicon resin content is $0.8 \%$ of the total mass of the products. 


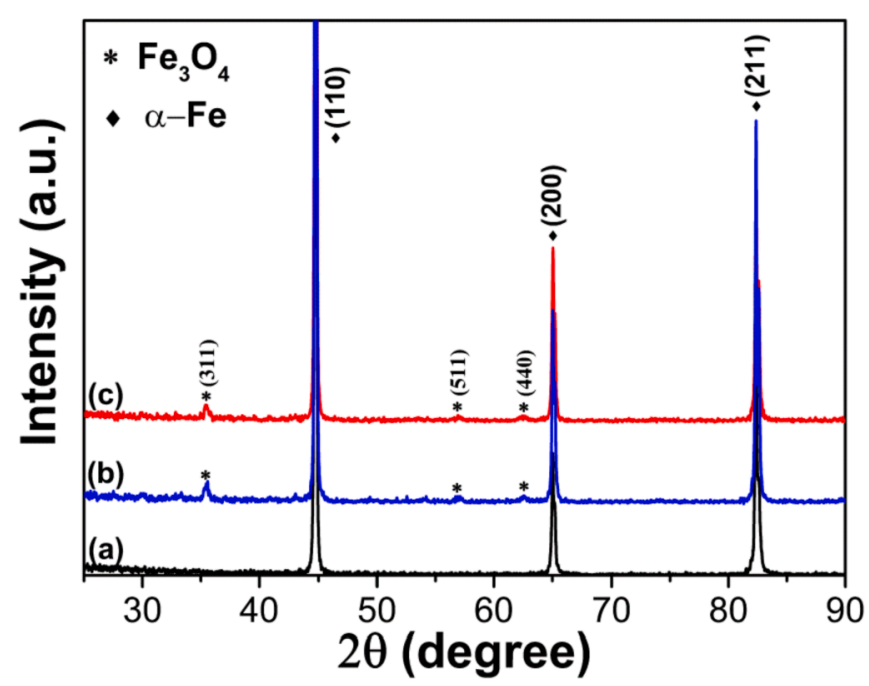

Fig. 2. Typical XRD patterns for original micron-sized Fe powders (a), the properly oxidized samples fabricated at $450{ }^{\circ} \mathrm{C}$ for $50 \mathrm{~min}$ (b) and the composites coated with silicon resin (c).

\subsection{Material structure characterization}

A D/max 2500 PC X-ray diffractometer (XRD, Cu K $\alpha$ with $\lambda=1.5406$ $\AA$ ) was used to examine the phase structures for the samples. The morphologies and microstructures for the samples were investigated using a JEOL JSM-7500F field emission scanning electron microscope (FESEM) along with a JEOL JEM-2100 transmission-electron microscope (TEM). A focused ion beam (FIB) technique was used for preparing the TEM samples of $\mathrm{Fe} / \mathrm{Fe}_{3} \mathrm{O}_{4}$ composites for cross-section observation. The surface elemental states for the samples were detected by an X-ray photoelectron spectroscopy (XPS, ESCALAB 250Xi).

\subsection{TRS and magnetic measurements}

The TRS values for the fully compacted samples were measured by a three-point bending test using a compression testing machine. A LakeShore-7410 vibrating sample magnetometer (VSM) was used for measuring intrinsic magnetic properties for the samples under a maximum applied magnetic field reaching $10 \mathrm{kOe}$ at room temperature. To measure the alternating-current (ac) and direct-current (dc) soft magnetic performance for the composites, the densified toroidal products with a $20-\mathrm{mm}$ outer diameter, a $10-\mathrm{mm}$ inner diameter and a 3.6$\mathrm{mm}$ sample thickness were prepared by directly compressing the $\mathrm{Fe} /$ $\mathrm{Fe}_{3} \mathrm{O}_{4}$ /resin composites at a pressure of $1200 \mathrm{MPa}$ with no any lubricants. An Archimedes method was used to measure the density for the fully compacted products. The total core loss for toroidal samples tested at frequencies of 50-1000 $\mathrm{Hz}$ under an applied maximum induction with $1 \mathrm{~T}$ and their magnetic inductions tested at magnetic fields of $1200-10000 \mathrm{~A} / \mathrm{m}$ were measured using an ac and dc test equipment for measuring magnetic hysteresis loops of soft magnets (provided by the National Institute of Metrology, China). A precision impedance analyzer (Agilent 4294A) was used to measure frequency-dependent magnetic characteristics of the products at a maximum applied frequency reaching $200 \mathrm{kHz}$.

\section{Results and discussion}

Fig. 2 presents the typical XRD patterns for the original micron-sized Fe powders, the properly oxidized products and the composites coated with silicon resin. From Fig. 2a, the original Fe powders display obvious XRD diffraction peaks located at three diffraction angles of $44.6^{\circ}, 65.2^{\circ}$ and $82.3^{\circ}$, which is in good agreement with the (110), (200) and (211)

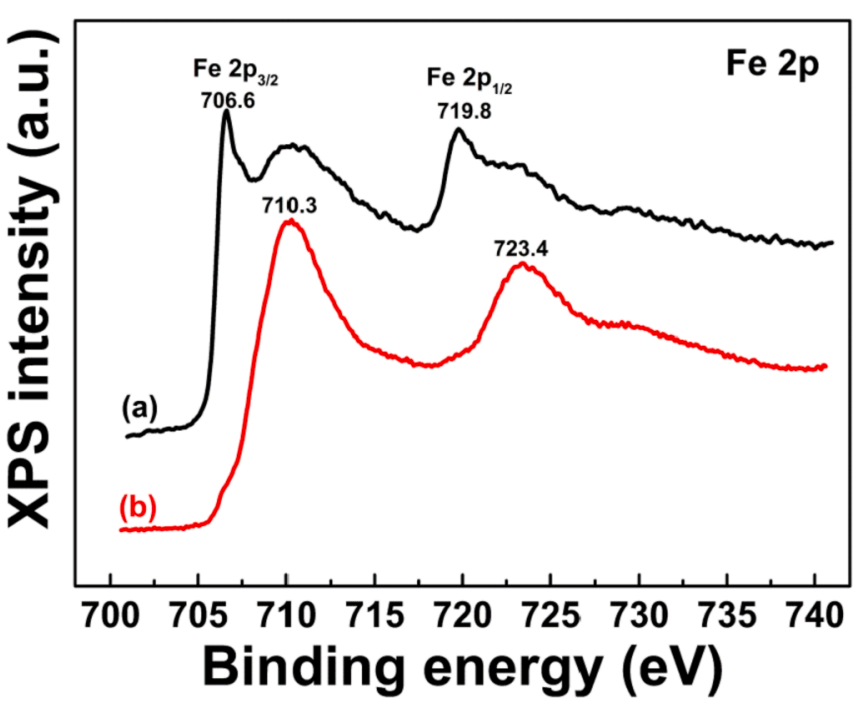

Fig. 3. Fe 2p XPS narrow-scan spectrums for original micron-sized Fe powders (a) and properly oxidized products fabricated at $450{ }^{\circ} \mathrm{C}$ for $50 \mathrm{~min}$ (b).

crystal planes of the single bcc-Fe phase. From Fig. $2 \mathrm{~b}$ and c, the XRD diffraction peaks of the silicon resin-coated oxidized particles are almost the same as those of the initially-oxidized particles due to the low resin silicon content $(0.8 \mathrm{wt} \%)$ in this resin-coated sample, which shows that no further oxidation occurs during the resin coating process. For these two products, apart from the bcc-Fe characteristic peaks, all the remaining peaks are well indexed to a fcc- $\mathrm{Fe}_{3} \mathrm{O}_{4}$ phase, the lattice constant for which $(8.3961 \AA$ ) nearly approaches that (8.3963 $\mathrm{A}$ ) for bulk $\mathrm{Fe}_{3} \mathrm{O}_{4}$ [29]. This indicates that pure $\mathrm{Fe}_{3} \mathrm{O}_{4}$ layers are in situ formed on the surfaces of unoxidized Fe parts by oxidizing high-purity Fe powders under a suitable oxidation environment. As discussed below, both high saturation magnetization and decreased core loss are achieved in these two Fe-based SMCs containing high-purity $\mathrm{Fe}_{3} \mathrm{O}_{4}$ layers due to their ferrimagnetism and relatively high resistivity.

As is known, the $\mathrm{Fe}_{3} \mathrm{O}_{4}$ phase exhibits almost the same XRD patterns but different XPS spectrums with those of $\gamma-\mathrm{Fe}_{2} \mathrm{O}_{3}$ phase [30,31]. The Fe chemical states for the initially-oxidized sample and original high-purity Fe powders have been examined with their XPS spectrums illustrated in Fig. 3. From Fig. 3a, two obvious Fe $2 \mathrm{p}$ XPS peaks $\left(\mathrm{Fe} 2 \mathrm{p}_{3 / 2}\right.$ located at $\sim 706.6 \mathrm{eV}$ accompanying with Fe $2 \mathrm{p}_{1 / 2}$ located at $\sim 719.8 \mathrm{eV}$ ) for the original Fe particles shows a pure Fe state [32]. An obvious broad bump located at $\sim 711.3 \mathrm{eV}$ in Fig. 3a is probably related to $\mathrm{Fe}^{2+}$ ions $[33,34]$, which is attributed to the very weak surface Fe oxidation for the original materials. Furthermore, only two obvious Fe 2p XPS peaks located at $\sim 723.8 \mathrm{eV}$ for $\mathrm{Fe} 2 \mathrm{p}_{1 / 2}$ and at $\sim 710.3 \mathrm{eV}$ for $\mathrm{Fe} 2 \mathrm{p}_{3 / 2}$ observed in Fig. $3 \mathrm{~b}$ for the oxidized product indicate the presence of high-purity $\mathrm{Fe}_{3} \mathrm{O}_{4}$ but no formation of $\gamma-\mathrm{Fe}_{2} \mathrm{O}_{3}$ phases on the surfaces of this initially-oxidized sample [35]. The XPS results for the oxidized products accord well with the above XRD investigation and further proved the in-situ formation of single-phase $\mathrm{Fe}_{3} \mathrm{O}_{4}$ layers on the surfaces of high-purity $\mathrm{Fe}$ powders processed under the controllable oxidation conditions.

Fig. $4 \mathrm{a}-\mathrm{c}$ presents the representative SEM images for the original $\mathrm{Fe}$ particles, the $\mathrm{Fe} / \mathrm{Fe}_{3} \mathrm{O}_{4}$ composites and the $\mathrm{Fe} / \mathrm{Fe}_{3} \mathrm{O}_{4} /$ resin composites. The $\mathrm{Fe} / \mathrm{Fe}_{3} \mathrm{O}_{4}$ composites show very similar morphologies with those of the original Fe particles. However, different appearance color can be observed in these two samples with light gray for original Fe powders changed to dark blue for the oxidized powders, which is believed to result from the $\mathrm{Fe}_{3} \mathrm{O}_{4}$ coating layers. Moreover, the resin coating layers are completely and uniformly coated on the surface of $\mathrm{Fe} / \mathrm{Fe}_{3} \mathrm{O}_{4}$ particles, which also result in their apparent color change from dark blue to dark gray for $\mathrm{Fe} / \mathrm{Fe}_{3} \mathrm{O}_{4} /$ resin composites. To further investigate microstructures of the $\mathrm{Fe} / \mathrm{Fe}_{3} \mathrm{O}_{4}$ core-shell particles, An FIB technique was applied to prepare their cross-section TEM samples. For protecting the 


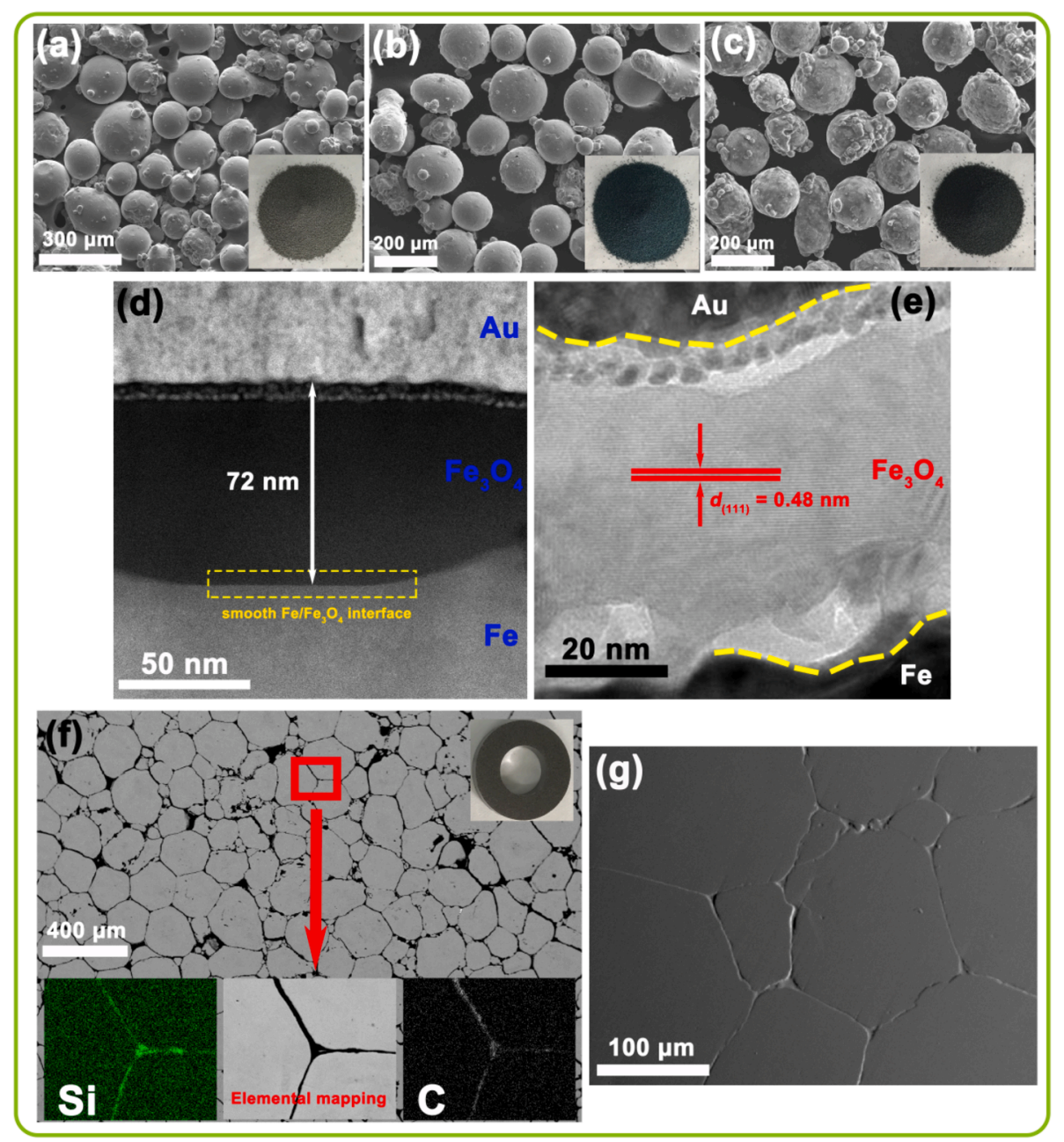

Fig. 4. Representative SEM images for original Fe powders (a), the $\mathrm{Fe} / \mathrm{Fe}_{3} \mathrm{O}_{4}$ composites (b) and the $\mathrm{Fe} / \mathrm{Fe}_{3} \mathrm{O}_{4} /$ resin composites (c), the cross-section TEM (d) and HRTEM (e) images for one typical $\mathrm{Fe} / \mathrm{Fe}_{3} \mathrm{O}_{4}$ core-shell particle, and the back-scattered electron images with compositional (f) or topographic ( $\mathrm{g}$ ) contrast of the cross section of the fully compacted $\mathrm{Fe} / \mathrm{Fe}_{3} \mathrm{O}_{4} /$ resin composites.

sample surface of $\mathrm{Fe} / \mathrm{Fe}_{3} \mathrm{O}_{4}$ particles for TEM observation from the FIB disruption, the Au layers of appropriate thickness were sprayed upon the surfaces of the initially-oxidized powders using a special sputter coater. Fig. 4d shows a representative cross-section TEM image for one typical initially-oxidized particle, which shows a distinct $\mathrm{Fe} / \mathrm{Fe}_{3} \mathrm{O}_{4}$ core-shell structure with 70 -nm thick $\mathrm{Fe}_{3} \mathrm{O}_{4}$ shells. Moreover, as also showed in Fig. 4d, the observation of no obvious cracks or pores but a very dense and smooth state for $\mathrm{Fe} / \mathrm{Fe}_{3} \mathrm{O}_{4}$ interface in initially-oxidized products indicates their good interface continuity, which is sure to lead to their high compaction density and low coercivity of the two composites as discussed below. The typical HRTEM image of the $\mathrm{Fe} / \mathrm{Fe}_{3} \mathrm{O}_{4}$ composites illustrated in Fig. 4e shows the single HRTEM diffraction patterns of $\mathrm{Fe}_{3} \mathrm{O}_{4}$ phase with the measured interplanar spacing value of $0.48 \mathrm{~nm}$ matching closely with the distances for the (111) planes [36]. The TEM results also confirm the in situ formation of single-phase $\mathrm{Fe}_{3} \mathrm{O}_{4}$ layers on the surfaces of high-purity Fe particles during their controlled oxidation. To further investigate the interface structures of silicon resin coated composites, the back-scattered electron images with compositional (BSE-COMP) or topographic (BSE-TOPO) contrast of the cross section of the fully $\mathrm{Fe} / \mathrm{Fe}_{3} \mathrm{O}_{4} /$ resin samples are observed as shown in Fig. $4 \mathrm{f}$ and $\mathrm{g}$. From the BSE-COMP image in Fig. 4f, a uniform interface with deformed composite particles isolated from each other by the coating layers is observed in the densified $\mathrm{Fe} / \mathrm{Fe}_{3} \mathrm{O}_{4} /$ resin sample. From the elemental mapping of a selected interface area inserted in Fig. 4f, the $\mathrm{Si}$ and $\mathrm{C}$ elements originating from silicon resin are concentrated between the interface of deformed particles, which indicates that silicon-resin shells are uniformly coated on the surfaces of the oxidized particles. The suitable amount of silicon resin coating layers in the $\mathrm{Fe} / \mathrm{Fe}_{3} \mathrm{O}_{4} /$ resin composites may act as a lubricant during their compaction to improve their mechanical properties with high TRS values, and can also act as the grain boundaries with relatively high resistivity to greatly reduce their magnetic loss as discussed below. From the BSE-TOPO image in Fig. $4 \mathrm{~g}$, the fully compressed $\mathrm{Fe} / \mathrm{Fe}_{3} \mathrm{O}_{4} /$ resin composites also show good compactness with no obvious cracks between the interfaces of deformed particles, which would lead to their high compaction density so as to improve their relatively high magnetic inductions as investigated later.

As is known, high compaction density is an important material parameter for metal-based SMCs, which is correlated with their high magnetic induction. Generally, low density of common organic and inorganic coating layers (epoxy resin, $\mathrm{SiO}_{2}, \mathrm{MgO}$ and $\mathrm{Al}_{2} \mathrm{O}_{3}$ et al.) in metal-based SMCs would inevitably decrease their compaction density [17]. However, good interface continuity exhibiting no apparent cracks or pores between material interfaces in the composites can maintain their relatively high compaction density [9]. In this work, a very high compacted density value $\left(7.55 \mathrm{~g} / \mathrm{cm}^{3}\right)$ achieved for fully compacted $\mathrm{Fe} / \mathrm{Fe}_{3} \mathrm{O}_{4}$ composites nearly approaches that $\left(7.68 \mathrm{~g} / \mathrm{cm}^{3}\right)$ of high-purity $\mathrm{Fe}$ powder cores compressed at the same pressures of $1200 \mathrm{MPa}$, which is attributed to good interfacial continuity of the dense $\mathrm{Fe} / \mathrm{Fe}_{3} \mathrm{O}_{4}$ core-shell structure as discussed in Fig. 4. The fully compacted $\mathrm{Fe} / \mathrm{Fe}_{3} \mathrm{O}_{4} /$ resin composites also achieve a relatively a high density value 


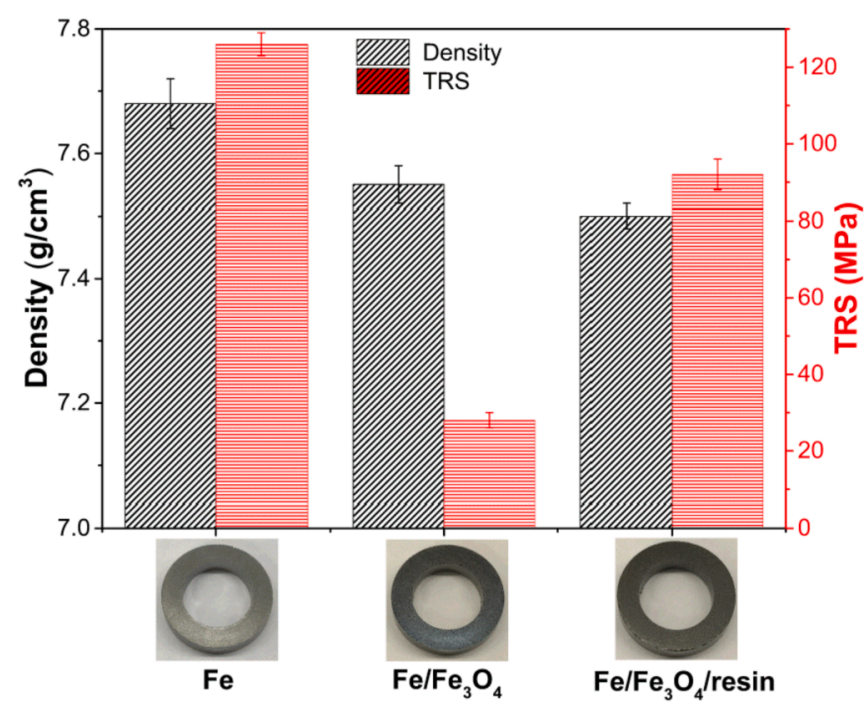

Fig. 5. The density and TRS values of the three compacted samples from the original $\mathrm{Fe}$ particles, the $\mathrm{Fe} / \mathrm{Fe}_{3} \mathrm{O}_{4}$ composites and the $\mathrm{Fe} / \mathrm{Fe}_{3} \mathrm{O}_{4} /$ resin composites.

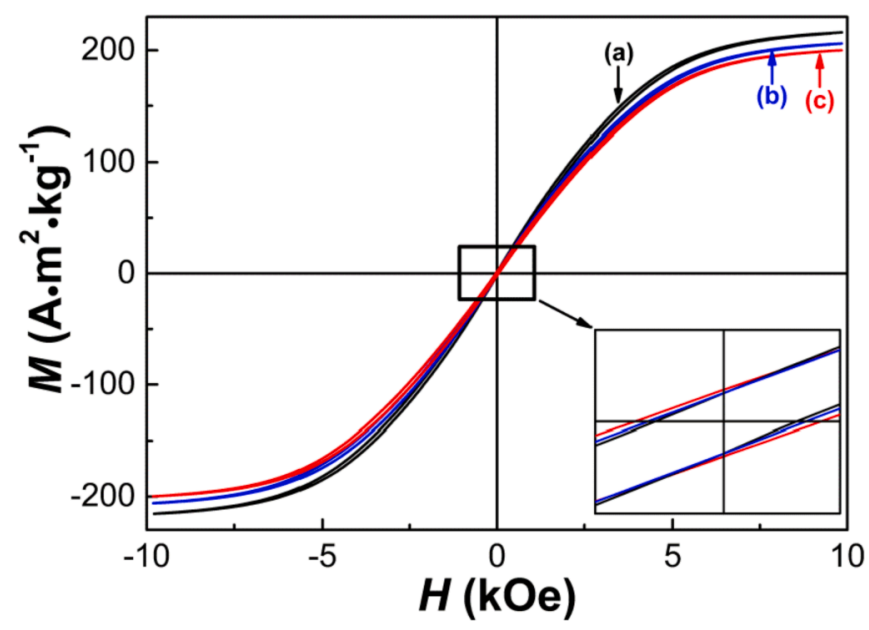

Fig. 6. Hysteresis loops tested under room temperature for the original $\mathrm{Fe}$ powders (a), the initially-oxidized $\mathrm{Fe} / \mathrm{Fe}_{3} \mathrm{O}_{4}$ particles (b) and the $\mathrm{Fe} / \mathrm{Fe}_{3} \mathrm{O}_{4}$ / resin composites (c).

of $7.50 \mathrm{~g} / \mathrm{cm}^{3}$ because of low content resin coated on surfaces of the initially-oxidized composites. High TRS values is another important use requirement for metal-based SMCs. From Fig. 5, the fully compacted Fe powder core exhibits a high TRS value of $126 \mathrm{MPa}$ due to good compacting ability of high-purity Fe particles. However, the compacted $\mathrm{Fe} / \mathrm{Fe}_{3} \mathrm{O}_{4}$ composites show a very low TRS value of $28 \mathrm{MPa}$, which is believed to result from deformation inconsistency of the ceramic $\mathrm{Fe}_{3} \mathrm{O}_{4}$ coating layers and unoxidized Fe parts in the composites. It is interesting to point out that a high TRS value of $92 \mathrm{MPa}$ can be obtained in the compressed $\mathrm{Fe} / \mathrm{Fe}_{3} \mathrm{O}_{4} /$ resin SMCs indicating their better compacting ability. A suitable amount of silicon resin coated on the surface of $\mathrm{Fe} / \mathrm{Fe}_{3} \mathrm{O}_{4}$ particles may act as a lubricant during the compaction, which would be beneficial to deformation between the composite particles and promote the contact and occlusion of deformed particles so as to lead to the higher TRS value for the fully compacted $\mathrm{Fe} / \mathrm{Fe}_{3} \mathrm{O}_{4} /$ resin SMCs. It can be concluded that both high density and high TRS value can be achieved in the compacted Fe-based SMCs by coating the oxidized metal particles with an appropriate amount of silicone resin layers, which can promote their practical applications in magnetic devices. As discussed below, the resin coating can also increase the resistivity of

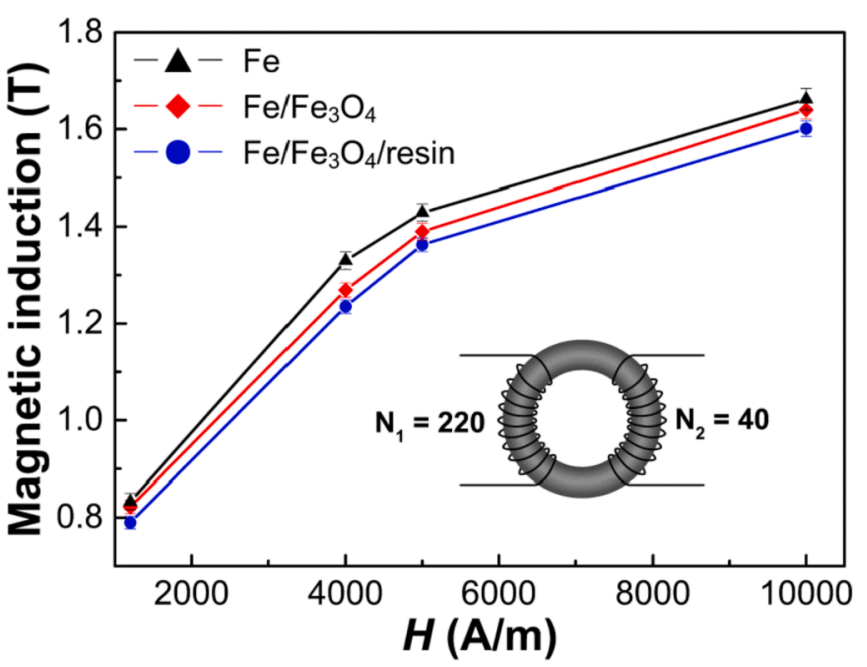

Fig. 7. DC magnetic induction $(B)$ values for three toroidal samples compacted from the $\mathrm{Fe} / \mathrm{Fe}_{3} \mathrm{O}_{4} /$ resin SMCs, the $\mathrm{Fe} / \mathrm{Fe}_{3} \mathrm{O}_{4}$ composites and the original Fe particles.

$\mathrm{Fe} / \mathrm{Fe}_{3} \mathrm{O}_{4} /$ resin SMCs and result in their low core loss.

Fig. 6 displays the hysteresis loops for the original Fe particles, the initially-oxidized $\mathrm{Fe} / \mathrm{Fe}_{3} \mathrm{O}_{4}$ particles and the $\mathrm{Fe} / \mathrm{Fe}_{3} \mathrm{O}_{4} /$ resin composites measured under room temperature. All the three samples show typical single-phase magnetic hysteresis along with good intrinsic magnetism. The $\mathrm{Fe} / \mathrm{Fe}_{3} \mathrm{O}_{4}$ core-shell particles show a high saturated magnetization value $\left(M_{\mathrm{s}}=206 \mathrm{~A} \mathrm{~m}^{2} \mathrm{~kg}^{-1}\right)$, very close to that $\left(214 \mathrm{~A} \mathrm{~m}^{2} \mathrm{~kg}^{-1}\right)$ for the original $\mathrm{Fe}$ particles because of the presence of 70-nm thick ferrimagnetic $\mathrm{Fe}_{3} \mathrm{O}_{4}$ shells. A relatively high $M_{\mathrm{s}}$ value reaching $201 \mathrm{~A} \mathrm{~m}^{2} \mathrm{~kg}^{-1}$ is maintained for $\mathrm{Fe} / \mathrm{Fe}_{3} \mathrm{O}_{4} /$ resin composites due to the $0.8 \mathrm{wt} \%$ silicon resin coating layers. It has been reported that seriously decreased $M_{\mathrm{s}}$ values along with low compacted density would occur in conventional SMCs prepared from coating metal-based magnetic powders with some insulating organic [37] and inorganic coating layers containing $\mathrm{MgO}$ [38] or $\mathrm{SiO}_{2}$ [39] because of the nonmagnetism along with low density for these coating layers. In this work, high $M_{\mathrm{S}}$ values accompanying with high compaction density are maintained in $\mathrm{Fe} / \mathrm{Fe}_{3} \mathrm{O}_{4} /$ resin SMCs due to the existence of nanoscale thick ferrimagnetic $\mathrm{Fe}_{3} \mathrm{O}_{4}$ layers and suitable amount of silicon resin layers properly coated on the surfaces of initially-oxidized $\mathrm{Fe} / \mathrm{Fe}_{3} \mathrm{O}_{4}$ particles. From Fig. 6, the two composites show low coercivity value of 9.6 Oe for $\mathrm{Fe} / \mathrm{Fe}_{3} \mathrm{O}_{4}$ composites and 11.4 Oe for $\mathrm{Fe} / \mathrm{Fe}_{3} \mathrm{O}_{4}$ /resin SMCs, close to that (8.9 Oe) for high-purity $\mathrm{Fe}$ powders. It is reported that compared with high-purity FeSi powder cores, a much higher coercivity occurs in the $\mathrm{FeSi} / \mathrm{SiO}_{2}$ core-shell composites prepared by a chemical deposition because of the pores and air gaps existing between $\mathrm{SiO}_{2}$ shells and $\mathrm{FeSi}$ cores, which hinder the movement of magnetic domain walls in the composites under their magnetization [40]. As shown in Fig. 4e, the tightly integrated $\mathrm{Fe} / \mathrm{Fe}_{3} \mathrm{O}_{4}$ interfaces with in situ formation of nanoscale thick $\mathrm{Fe}_{3} \mathrm{O}_{4}$ layers coated on the surfaces of unoxidized Fe parts can probably decrease some interface defects containing holes or stress, which can improve magnetic domain movement so as to result in their low coercivity in these two composites. Moreover, the possible magnetic interaction occurring between two magnetic crystallographically coherent $\mathrm{Fe}$ and $\mathrm{Fe}_{3} \mathrm{O}_{4}$ phases in these two composites reduces movement resistance of magnetic domains and further promote their low coercivity $[9,16]$. A small amount of silicone resin coating layers do not significantly increase the coercivity of the $\mathrm{Fe} / \mathrm{Fe}_{3} \mathrm{O}_{4}$ /resin SMCs, which may be ascribed to the uniform and complete resin coating upon the surfaces of the oxidized particles.

Fig. 7 presents dc magnetic induction $(B)$ values for three toroidal samples tested with a closed-loop mode at maximum external magnetic fields $(H)$ in a range of $1200-10000 \mathrm{~A} / \mathrm{m}$. From the inset of Fig. 7, the 

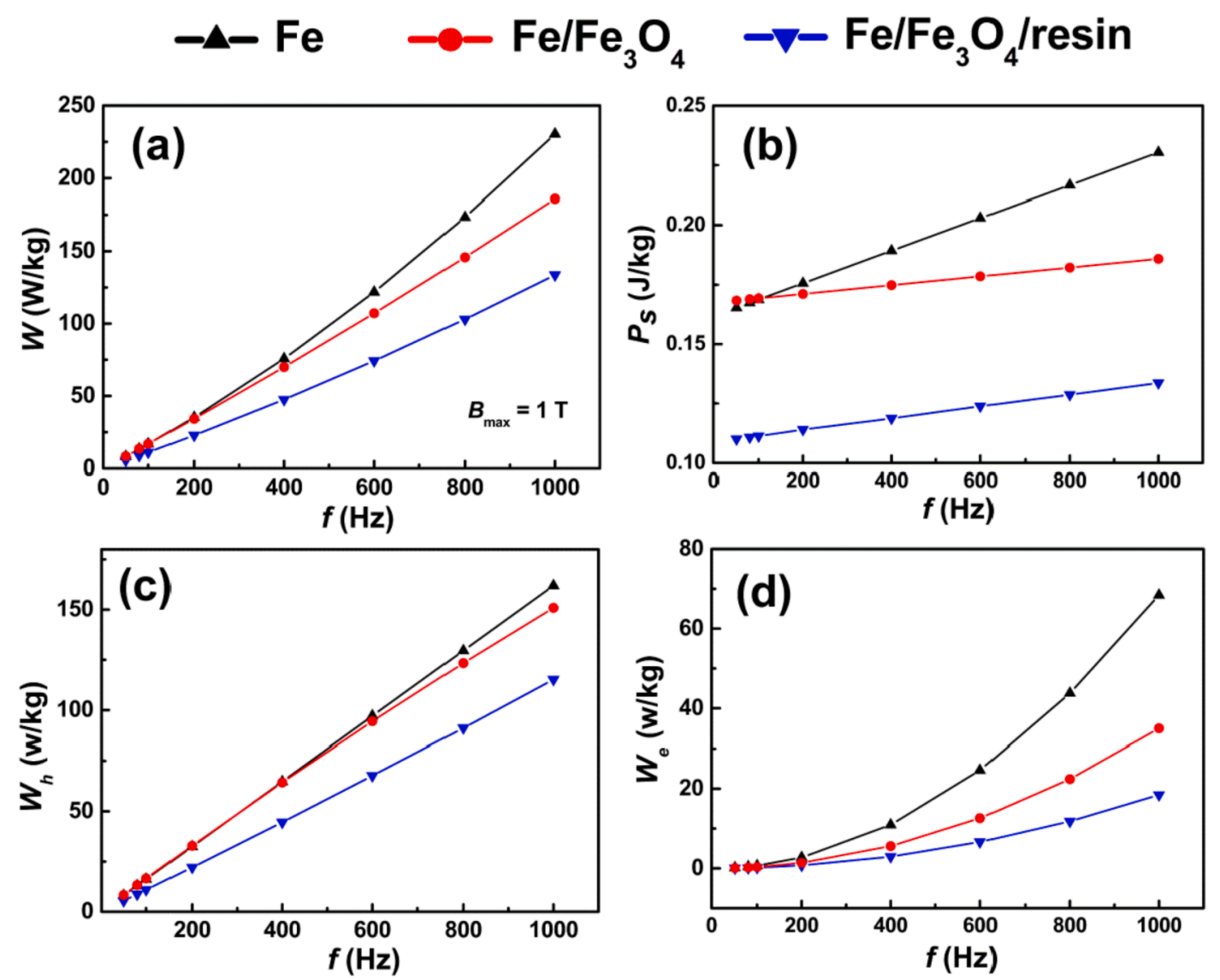

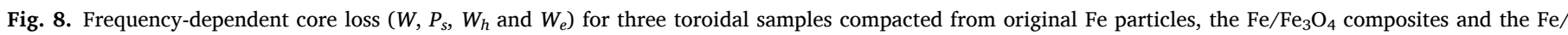
$\mathrm{Fe}_{3} \mathrm{O}_{4} /$ resin SMCs tested at an applied magnetic induction with $1 \mathrm{~T}$.

turn numbers ( $\mathrm{N}_{1}$ for primary and $\mathrm{N}_{2}$ for secondary coils) for the magnetic induction measurement are 220 and 40, respectively. The two compacted composites show slightly decreased $B$ values tested at the same $H$ of $1200-10000 \mathrm{~A} / \mathrm{m}$ than those for high-purity Fe powder cores, which is mainly ascribed to the magnetic dilution of the coating layers. Nevertheless, high magnetic inductions varying from 0.8 to $1.6 \mathrm{~T}$ measured at $H$ increased from 1200 to $10000 \mathrm{~A} / \mathrm{m}$ are sustained for the $\mathrm{Fe} / \mathrm{Fe}_{3} \mathrm{O}_{4} /$ resin SMCs, which is attributed to the existence of high-purity ferrimagnetic $\mathrm{Fe}_{3} \mathrm{O}_{4}$ nanolayers. As discussed above, high compaction density for $\mathrm{Fe} / \mathrm{Fe}_{3} \mathrm{O}_{4} /$ resin SMCs also promotes their relatively high magnetic inductions. The present metal-based SMCs with decreased core loss have been prepared from coating metal-based magnetic particles using some insulating organic and inorganic layers containing resin, $\mathrm{MgO}$ and $\mathrm{SiO}_{2}$. However, seriously decreased $B$ values would occur in these conventional SMCs due to nonmagnetism of these coating layers [41-43], which always impedes their practical usages for high-power situations. In the present work, high $B$ values are achieved in the $\mathrm{Fe} / \mathrm{Fe}_{3} \mathrm{O}_{4} /$ resin SMCs because of the presence of nanoscale thick ferrimagnetic $\mathrm{Fe}_{3} \mathrm{O}_{4}$ layers and suitable amount of resin layers can overcome the disadvantages of conventional SMCs and promise their actual applications for high-power and low-loss magnetic components.

Fig. 8 presents the frequency-dependent core loss $\left(W-f, P_{s}-f, W_{h}-f\right.$ and $W_{e}-f$ curves) tested at an applied induction with $1 \mathrm{~T}$ for three toroidal samples compacted from the original Fe particles, the $\mathrm{Fe} / \mathrm{Fe}_{3} \mathrm{O}_{4}$ composites and the $\mathrm{Fe} / \mathrm{Fe}_{3} \mathrm{O}_{4} /$ resin SMCs. As shown in Fig. 8a and b, in general, both of the two composites show greatly decreased $W$ and $P_{\mathrm{S}}$ values ( $W$ is defined as total core loss, and $P_{\mathrm{s}}$ is defined as per-cycle core loss expressed as $W / f$ ) than those for high-purity Fe powder cores compressed from original $\mathrm{Fe}$ particles. Moreover, the resin coating leads to greatly decreased core loss in the $\mathrm{Fe} / \mathrm{Fe}_{3} \mathrm{O}_{4}$ /resin SMCs than that of the $\mathrm{Fe} / \mathrm{Fe}_{3} \mathrm{O}_{4}$ composites. For the investigation of the loss mechanism of the samples, the total core loss $W$ is divided into eddy-current loss $\left(W_{e}\right)$ and hysteresis loss $\left(W_{\mathrm{h}}\right)$ according to an experiential formula expressed as follows:

$W=W_{h}+W_{e}=e B_{m}^{2} f^{2}+\eta \mathbf{B}_{m}^{1.6} f$

where $f$ is applied frequencies, $B_{m}$ is an applied maximum magnetic induction, $\eta$ is a material constant and $e$ is a loss coefficient. It should be pointed out that very low residual loss measured at $f$ beyond $1000 \mathrm{~Hz}$ is ignored in this work. Moreover, the $P_{s}-f$ curves for all the three toroidal samples as shown in Fig. $8 \mathrm{~b}$ show an obvious linear characteristic, which indicates that the two loss terms $\left(W_{h}\right.$ and $\left.W_{e}\right)$ dominates total loss $W$ for these samples [15]. Therefore, the loss $W_{h}$ and $W_{e}$ is separated from measured core loss $W$ based on formula (2) as illustrated respectively in Fig. $8 \mathrm{c}$ and $\mathrm{d}$.

The hysteresis loss as shown in Fig. 8c dominates total loss $W$ for three samples measured at low frequencies, and their eddy-current loss as shown in Fig. 8d increases much more quickly than hysteresis loss does with increasing applied frequencies. Moreover, the eddy-current $W_{e}$ for the compacted $\mathrm{Fe} / \mathrm{Fe}_{3} \mathrm{O}_{4}$ composites is comparably lower than that for high-purity Fe powder cores. The obviously decreased eddycurrent loss for $\mathrm{Fe} / \mathrm{Fe}_{3} \mathrm{O}_{4}$ composites is mainly attributed to much higher resistivity for the $\mathrm{Fe}_{3} \mathrm{O}_{4}$ shells $\left(1 \times 10^{-2} \Omega \mathrm{cm}\right)$ [23] than that $(1$ $\times 10^{-7} \Omega \mathrm{cm}$ ) for high-purity Fe [44], for the high resistivity for powder grains of soft magnetic materials is sure to greatly inhibit their eddy current loss [45]. However, compared with high-purity powder cores, the loss terms $W_{h}$ for $\mathrm{Fe} / \mathrm{Fe}_{3} \mathrm{O}_{4}$ composites is slightly decreased and still maintains higher loss values. As discussed in Fig. 5, the inconsistent deformation between $\mathrm{Fe} / \mathrm{Fe}_{3} \mathrm{O}_{4}$ core-shell interfaces leads to their low bonding strength resulting in low TRS value for compressed $\mathrm{Fe} / \mathrm{Fe}_{3} \mathrm{O}_{4}$ composites. So the relatively high $W_{h}$ for $\mathrm{Fe} / \mathrm{Fe}_{3} \mathrm{O}_{4}$ composites can be 


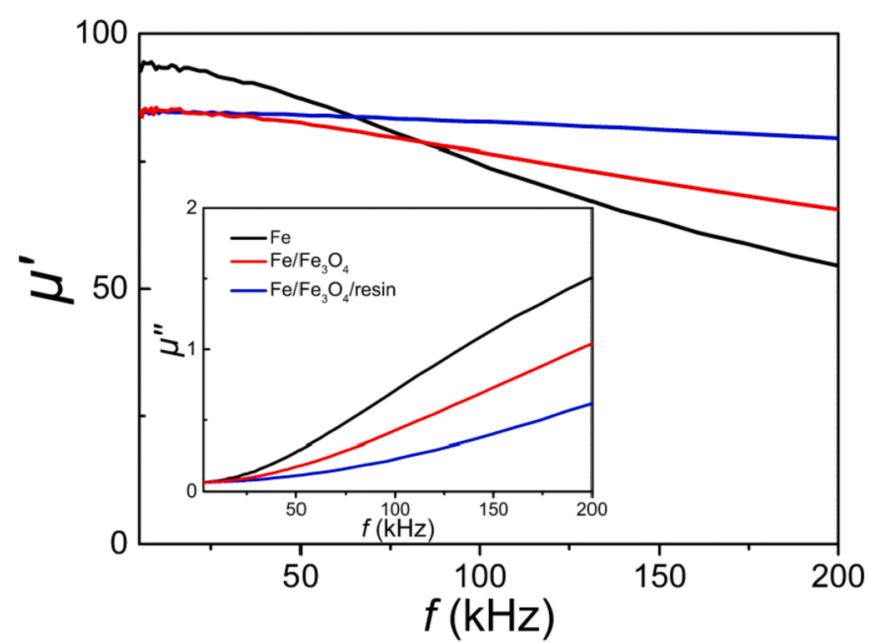

Fig. 9. Complex permeability spectrums for three toroidal samples compacted from the $\mathrm{Fe} / \mathrm{Fe}_{3} \mathrm{O}_{4} /$ resin SMCs, $\mathrm{Fe} / \mathrm{Fe}_{3} \mathrm{O}_{4}$ composites and original high-purity Fe particles.

probably attributed to the occurrence of increased internal stress for the compressed $\mathrm{Fe} / \mathrm{Fe}_{3} \mathrm{O}_{4}$ composites due to inconsistent deformation between the ceramic $\mathrm{Fe}_{3} \mathrm{O}_{4}$ nanolayers and unoxidized $\mathrm{Fe}$ parts [16]. As showed in Fig. 8c, the loss terms $W_{e}$ for $\mathrm{Fe} / \mathrm{Fe}_{3} \mathrm{O}_{4} /$ resin SMCs can be further greatly reduced by coating the oxidized particles with $0.8 \mathrm{wt} \%$ silicone resin, which is sure to result from the increased resistivity of the composites due to the existence of resin layers. It is worth pointing out that the loss terms $W_{h}$ for $\mathrm{Fe} / \mathrm{Fe}_{3} \mathrm{O}_{4} /$ resin SMCs is also greatly decreased, which can be attributed to their reduced interfacial defects such as holes and cracks between Fe cores and the coating layers in the fully compacted sample as discussed in Fig. 4.

Fig. 9 shows the complex permeability with real part of $\mu^{\prime}$ accompanying with imaginary part of $\mu$ " versus frequency for three toroidal products tested at different frequencies ranging from 40 to $200 \mathrm{KHz}$. From Fig. 9, desirable frequency-dependent soft magnetic performance is observed for the $\mathrm{Fe} / \mathrm{Fe}_{3} \mathrm{O}_{4}$ /resin SMCs due to the successive uniform resin layers coated on the surfaces of the initially oxidized particles. Moreover, the $\mathrm{Fe} / \mathrm{Fe}_{3} \mathrm{O}_{4} /$ resin SMCs exhibit decreased $\mu^{\prime}$ values slightly lower than those for high-purity Fe powder cores tested at frequencies beyond $60 \mathrm{KHz}$, and however, high $\mu^{\prime}$ values are maintained for the composites when measured at frequencies ranging from 60 to $200 \mathrm{KHz}$, which implies that the composites possess an improved ac permeability. A gradual descending trend can be also observed in $\mu^{\prime}-f$ curve for the $\mathrm{Fe} /$ $\mathrm{Fe}_{3} \mathrm{O}_{4}$ /resin SMCs and very low $\mu$ " values can be simultaneously obtained at applied frequencies reaching $200 \mathrm{KHz}$, which further indicates the decreased core loss for the $\mathrm{Fe} / \mathrm{Fe}_{3} \mathrm{O}_{4} /$ resin SMCs because of the increased resistivity of coating layers. Thus, among three samples, the $\mathrm{Fe} / \mathrm{Fe}_{3} \mathrm{O}_{4}$ /resin SMCs show best frequency-dependent magnetic performance containing low $\mu$ ' but high $\mu^{\prime}$ values under applied frequencies reaching $200 \mathrm{KHz}$. From the above mechanical and magnetic investigations, it is concluded that these $\mathrm{Fe} / \mathrm{Fe}_{3} \mathrm{O}_{4} /$ resin composites possess greatly improved overall performance with high density, high TRS and good soft magnetic characteristics, which can make them behave as new-type low-loss metal-based SMCs for high-power metalbased magnetic components.

\section{Conclusions}

A new type of $\mathrm{Fe} / \mathrm{Fe}_{3} \mathrm{O}_{4}$ /resin SMCs with reinforced structure has been prepared by properly oxidizing high-purity micron-sized Fe powders with 70-nm-thick $\mathrm{Fe}_{3} \mathrm{O}_{4}$ layers in situ formed on the surfaces of unoxidized Fe parts and then coating the initially oxidized products with $0.8 \mathrm{wt} \%$ silicone resin through a physical coating method. Good intrinsic magnetism containing a high saturated magnetization value $\left(201 \mathrm{~A} \mathrm{~m}^{2}\right.$ $\mathrm{kg}^{-1}$ ) in company with a low coercivity value (11.4 Oe) can be achieved in $\mathrm{Fe} / \mathrm{Fe}_{3} \mathrm{O}_{4} /$ resin SMCs because of the existence of single-phase ferrimagnetic $\mathrm{Fe}_{3} \mathrm{O}_{4}$ shells in company with uniform silicone resin coating layers. The fully compacted $\mathrm{Fe} / \mathrm{Fe}_{3} \mathrm{O}_{4} /$ resin SMCs possess good overall performance with high TRS value and greatly improved soft magnetic properties including high magnetic inductions, decreased core loss and desirable frequency-dependent magnetic characteristics because of the suitable coating of $\mathrm{Fe}_{3} \mathrm{O}_{4}$ and silicone resin with appropriate thickness, which is superior to that of high-purity Fe powder cores and traditional metal-based SMCs and promises their latent usages for high-power and low-loss magnetic devices.

\section{Declaration of competing interest}

All the authors declare no conflict of interest.

\section{Acknowledgements}

This work was supported by the National Natural Science Foundation of China (under Grant No. 51920105001 and 51101007) and the Beijing Natural Science Foundation (under Grant No. 2132039).

\section{References}

[1] H. Shokrollahi, K. Janghorban, Soft magnetic composite materials (SMCs), J. Mater. Process. Technol. 189 (2007) 1-12, https://doi.org/10.1016/j. jmatprotec.2007.02.034.

[2] J. Füzer, M. Strečková, S. Dobák, Ľ. Ďáková, P. Kollár, M. Fáberová, R. Bureš, Y. Osadchuk, P. Kurek, M. Vojtko, Innovative ferrite nanofibres reinforced soft magnetic composite with enhanced electrical resistivity, J. Alloy. Comp. 753 (2018) 219-227, https://doi.org/10.1016/j.jallcom.2018.04.237.

[3] J. Lei, J.W. Zheng, H.D. Zheng, L. Qiao, Y. Ying, W. Cai, W.C. Li, J. Yu, M. Lin, S. L. Che, Effects of heat treatment and lubricant on magnetic properties of iron-based soft magnetic composites with $\mathrm{Al}_{2} \mathrm{O}_{3}$ insulating layer by one-pot synthesis method, J. Magn. Magn. Mater. 472 (2019) 7-13, https://doi.org/10.1016/j. jmmm.2018.09.125.

[4] W.C. Li, H.W. Cai, Y. Kang, Y. Ying, J. Yu, J.W. Zheng, L. Qiao, Y. Jiang, S.L. Che, High permeability and low loss bioinspired soft magnetic composites with nacrelike structure for high frequency applications, Acta Mater. 167 (2019) 267-274, https://doi.org/10.1016/j.actamat.2019.01.035.

[5] Y. Yi, Y.D. Peng, C. Xia, L.Y. Wu, X. Ke, J.W. Nie, Influence of heat treatment on microstructures and magnetic properties of Fe-based soft magnetic composites prepared by co-precipitation method, J. Magn. Magn. Mater. 476 (2019) 100-105, https://doi.org/10.1016/j.jmmm.2018.12.049.

[6] J. Zhao, C. Wu, D.H. Luo, M. Yan, Soft magnetic composites based on the Fe elemental, binary and ternary alloy systems fabricated by surface nitridation, J. Magn. Magn. Mater. 481 (2019) 140-149, https://doi.org/10.1016/j. jmmm.2019.01.070.

[7] W.C. Li, Z.J. Wang, Y. Ying, J. Yu, J.W. Zheng, L. Qiao, S.L. Che, In-situ formation of $\mathrm{Fe}_{3} \mathrm{O}_{4}$ and $\mathrm{ZrO}_{2}$ coated Fe-based soft magnetic composites by hydrothermal method, Ceram. Int. 45 (2019) 3864-3870, https://doi.org/10.1016/j. ceramint.2018.11.058.

[8] B. Zhou, Y.Q. Dong, L. Liu, L. Chang, F.Q. Bi, X.M. Wang, Enhanced soft magnetic properties of the Fe-based amorphous powder cores with novel $\mathrm{TiO}_{2}$ insulation coating layer, J. Magn. Magn. Mater. 474 (2019) 1-8, https://doi.org/10.1016/j. jmmm.2018.11.014.

[9] B. Yang, X.P. Li, R.Y. Guo, R.H. Yu, Oxidation fabrication and enhanced soft magnetic properties for core-shell $\mathrm{FeCo} / \mathrm{CoFe}_{2} \mathrm{O}_{4}$ micron-nano composites, Mater. Des. 121 (2017) 272-279, https://doi.org/10.1016/j.matdes.2017.02.073.

[10] D.H. Luo, C. Wu, M. Yan, Incorporation of the $\mathrm{Fe}_{3} \mathrm{O}_{4}$ and $\mathrm{SiO}_{2}$ nanoparticles in epoxy-modified silicone resin as the coating for soft magnetic composites with enhanced performance, J. Magn. Magn. Mater. 452 (2018) 5-9, https://doi.org/ 10.1016/j.jmmm.2017.12.005.

[11] L.Y. Li, Z. Gao, A.K. Li, J.H. Yi, Y.C. Ge, Fabrication of carbonyl iron powder/SiO $/ \mathrm{S}^{-}$ reduced iron powder $/ \mathrm{SiO}_{2}$ soft magnetic composites with a high resistivity and low core loss, J. Magn. Magn. Mater. 464 (2018) 161-167, https://doi.org/10.1016/j. jmmm.2018.05.053.

[12] Z.G. Luo, X.A. Fan, W.T. Hu, F. Luo, G.Q. Li, Y.W. Li, X. Liu, J. Wang, Controllable $\mathrm{SiO}_{2}$ insulating layer and magnetic properties for intergranular insulating $\mathrm{Fe}$ 6.5wt.\%Si/ $/ \mathrm{SiO}_{2}$ composites, Adv. Powder Technol. 30 (2019) 538-543, https:// doi.org/10.1016/j.apt.2018.12.004.

[13] F. Luo, X.A. Fan, Z.G. Li, W.T. Hu, G.Q. Li, Y.W. Li, X. Liu, J. Wang, Ultra-low interparticle eddy current loss of $\mathrm{Fe}_{3} \mathrm{Si} / \mathrm{Al}_{2} \mathrm{O}_{3}$ soft magnetic composites evolved from $\mathrm{FeSiAl} / \mathrm{Fe}_{3} \mathrm{O}_{4}$ core-shell particles, J. Magn. Magn. Mater. 484 (2019) 218-224, https://doi.org/10.1016/j.jmmm.2019.04.027.

[14] W. Ding, L.T. Jiang, Y.Q. Liao, J.B. Song, B.Q. Li, G.H. Wu, Effect of iron particle size and volume fraction on the magnetic properties of $\mathrm{Fe}$ /silicate glass soft magnetic composites, J. Magn. Magn. Mater. 378 (2015) 232-238, https://doi.org/ 10.1016/j.jmmm.2014.09.019. 
[15] Y.W. Zhao, X.K. Zhang, J.Q. Xiao, Submicrometer laminated $\mathrm{Fe} / \mathrm{SiO}_{2}$ soft magnetic composites-an effective route to materials for high-frequency applications, Adv. Mater. 17 (2005) 915-918, https://doi.org/10.1002/adma.200401096.

[16] B. Yang, X.P. Li, X.Y. Yang, R.H. Yu, Chemical synthesis of $\mathrm{Fe} / \mathrm{Fe}_{3} \mathrm{O}_{4}$ core-shell composites with enhanced soft magnetic performances, J. Magn. Magn. Mater. (2017) 6-11, https://doi.org/10.1016/j.jmmm.2016.12.006.

[17] J.X. Li, J. Yu, W.C. Li, S.L. Che, J.W. Zheng, L. Qiao, Y. Ying, The preparation and magnetic performance of the iron-based soft magnetic composites with the Fe@ $\mathrm{Fe}_{3} \mathrm{O}_{4}$ powder of in situ surface oxidation, J. Magn. Magn. Mater. 454 (2018) 103-109, https://doi.org/10.1016/j.jmmm.2018.01.061.

[18] G.L. Zhao, C. Wu, M. Yan, Evolution of the insulation matrix and influences on the magnetic performance of Fe soft magnetic composites during annealing, J. Alloy. Comp. 685 (2016) 231-236, https://doi.org/10.1016/j.jallcom.2016.05.277.

[19] Z.G. Luo, X.A. Fan, W.T. Hu, F. Luo, G.Q. Li, Y.W. Li, X. Liu, J. Wang, Controllable $\mathrm{SiO}_{2}$ insulating layer and magnetic properties for intergranular insulating $\mathrm{Fe}-$ 6.5wt.\% $\mathrm{Si} / \mathrm{SiO}_{2}$ composites, Adv. Powder Technol. 30 (2019) 538-543, https:// doi.org/10.1016/j.apt.2018.12.004.

[20] X.X. Zhong, J.C. Chen, L. Wang, B.J. Li, L.Z. Li, Properties of FeSiAl-based soft magnetic composites with $\mathrm{AlN} / \mathrm{Al}_{2} \mathrm{O}_{3}$ and hybrid phosphate-silane insulation coatings, J. Alloy. Comp. 735 (2018) 1603-1610, https://doi.org/10.1016/j. jallcom.2017.11.312.

[21] S. Wu, A.Z. Sun, Z.W. Lu, C. Cheng, X.X. Gao, Magnetic properties of iron-based soft magnetic composites with $\mathrm{SiO}_{2}$ coating obtained by reverse microemulsion method, J. Magn. Magn. Mater. 381 (2015) 451-456, https://doi.org/10.1016/j. jmmm.2015.01.030.

[22] X.X. Zhong, Y. Liu, J. Li, Y.W. Wang, Structure and magnetic properties of FeSiAlbased soft magnetic composite with $\mathrm{AlN}$ and $\mathrm{Al}_{2} \mathrm{O}_{3}$ insulating layer prepared by selective nitridation and oxidation, J. Magn. Magn. Mater. 324 (2012) 2631-2636, https://doi.org/10.1016/j.jmmm.2012.03.026.

[23] K.J. Sunday, F.G. Hanejko, M.L. Taheri, Magnetic and microstructural properties of $\mathrm{Fe}_{3} \mathrm{O}_{4}$-coated Fe powder soft magnetic composites, J. Magn. Magn. Mater. 423 (2017) 164-170, https://doi.org/10.1016/j.jmmm.2016.09.024.

[24] L.W. Qian, J.G. Peng, Z. Xiang, Y.F. Pan, W. Lu, Effect of annealing on magnetic properties of $\mathrm{Fe} / \mathrm{Fe}_{3} \mathrm{O}_{4}$ soft magnetic composites prepared by in-situ oxidation and hydrogen reduction methods, J. Alloy. Comp. 778 (2019) 712-720, https://doi. org/10.1016/j.jallcom.2018.11.184.

[25] Z.G. Hou, P.F. Yan, B. Sun, H. Elshekh, B. Yan, An excellent soft magnetic Fe/ $\mathrm{Fe}_{3} \mathrm{O}_{4}$-FeSiAl composite with high permeability and low core loss, Results Phys. 14 (2019) 102498, https://doi.org/10.1016/j.rinp.2019.102498.

[26] B.Y. Meng, J.X. Hou, F.Z. Ning, B. Yang, B.H. Zhou, R.H. Yu, Low-loss and highinduction Fe-based soft magnetic composites coated with magnetic insulating layers, J. Magn. Magn. Mater. 492 (2019) 165651, https://doi.org/10.1016/j. jmmm.2019.165651.

[27] Y. Chen, L. Zhang, H.S. Sun, F.F. Chen, P. Zhang, X.H. Qu, E.D. Fan, Enhanced magnetic properties of iron-based soft magnetic composites with phosphatepolyimide insulating layer, J. Alloy. Comp. 813 (2020) 152205, https://doi.org/ 10.1016/j.jallcom.2019.152205.

[28] Y. Wu, B.Y. Meng, B. Yang, B.H. Zhou, C.L. Ren, R.H. Yu, Chemical coating of crystalline-Fe/amorphous-Fe core-shell structured composites and their enhanced soft magnetic properties, J. Magn. Magn. Mater. 494 (2020) 165774, https://doi. org/10.1016/j.jmmm.2019.165774.

[29] J. Li, H. Zeng, S.H. Sun, J.P. Liu, Z.L. Wang, Analyzing the structure of $\mathrm{CoFe}-\mathrm{Fe}_{3} \mathrm{O}_{4}$ core-shell nanoparticles by electron imaging and diffraction, J. Phys. Chem. B 108 (2004) 14005-14008, https://doi.org/10.1021/jp047602f.
[30] T. Fan, D.K. Pan, H. Zhang, Study on formation mechanism by monitoring the morphology and structure evolution of nearly monodispersed $\mathrm{Fe}_{3} \mathrm{O}_{4}$ submicroparticles with controlled particle sizes, Ind. Eng. Chem. Res. 50 (2011) 9009-9018, https://doi.org/10.1021/ie200970j.

[31] G.C. Xi, C. Wang, X. Wang, The oriented self-assembly of magnetic $\mathrm{Fe}_{3} \mathrm{O}_{4}$ nanoparticles into monodisperse microspheres and their use as substrates in the formation of $\mathrm{Fe}_{3} \mathrm{O}_{4}$ nanorods, Eur. J. Inorg. Chem. 2008 (2008) 425-431, https:// doi.org/10.1002/ejic.200700863.

[32] X.Y. Yang, B. Yang, X.P. Li, Y. Cao, R.H. Yu, Structural-controlled chemical synthesis of nanosized amorphous Fe particles and their improved performances, J. Alloy. Comp. 651 (2015) 551-556, https://doi.org/10.1016/j. jallcom.2015.08.156.

[33] B. Yang, X.Y. Yang, X.P. Li, Y. Cao, R.H. Yu, Surface modification and enhanced performance of chemically synthesized nanosized amorphous Fe particles, J. Supercond. Nov. Magnetism 28 (2015) 2177-2182, https://doi.org/10.1007/ s10948-015-3021-x.

[34] T. Yamashita, P. Hayes, Analysis of XPS spectra of $\mathrm{Fe}^{2+}$ and $\mathrm{Fe}^{3+}$ ions in oxide materials, Appl. Surf. Sci. 254 (2008) 2441-2449, https://doi.org/10.1016/j. apsusc.2007.09.063.

[35] B. Yang, X.Y. Yang, X.P. Li, Y. Cao, R.H. Yu, A facile solvothermal synthesis of large-grain iron cubes and cuboids with enhanced performances, J. Magn. Magn. Mater. 405 (2016) 22-27, https://doi.org/10.1016/j.jmmm.2015.12.049.

[36] H. Yu, M. Chen, P.M. Rice, S.X. Wang, R.L. White, S.H. Sun, Dumbbell-like bifunctional Au- $\mathrm{Fe}_{3} \mathrm{O}_{4}$ nanoparticles, Nano Lett. 5 (2005) 379-382, https://doi. org $/ 10.1021 / \mathrm{nl047955q.}$

[37] B.V. Neamţu, M. Nasui, T.F. Marinca, F. Popa, I. Chicinaş, Soft magnetic composites based on hybrid coated Fe-Si nanocrystalline powders, Surf. Coat. Technol. 330 (2017) 219-227, https://doi.org/10.1016/j.surfcoat.2017.09.088.

[38] L. Zhang, B. Yang, Y. Cao, R.H. Yu, Preparation and magnetic properties of novel hybrid magnetic powder cores, Mater. Res. Innov. 18 (2014) 610-614, https://doi. org/10.1179/1432891714Z.000000000754.

[39] A.H. Taghvaei, H. Shokrollahi, K. Janghorban, H. Abiri, Eddy current and total power loss separation in the iron-phosphate-polyepoxy soft magnetic composites, Mater. Des. 30 (2009) 3989-3995, https://doi.org/10.1016/j. matdes.2009.05.026.

[40] X.A. Fan, Z.Y. Wu, G.Q. Li, J. Wang, Z.D. Xiang, Z.H. Gan, High resistivity and low core loss of intergranular insulated $\mathrm{Fe}-6.5 \mathrm{wt} . \% \mathrm{Si} / \mathrm{SiO}_{2}$ composite compacts, Mater. Des. 89 (2016) 1251-1258, https://doi.org/10.1016/j.matdes.2015.10.087.

[41] T. Ishizaki, H. Nakano, S. Tajima, N. Takahashi, Improving powder magnetic core properties via application of thin, insulating silica-nanosheet layers on iron powder particles, Nanomaterials 7 (2017) 1, https://doi.org/10.3390/nano7010001.

[42] M. Strečková, Ľ. Medvecký, J. Füzer, P. Kollár, R. Bureš, M. Fáberová, Design of novel soft magnetic composites based on Fe/resin modified with silica, Mater. Lett. 101 (2013) 37-40, https://doi.org/10.1016/j.matlet.2013.03.067.

[43] A.H. Taghvaei, A. Ebrahimi, K. Gheisari, K. Janghorban, Analysis of the magnetic losses in iron-based soft magnetic composites with $\mathrm{MgO}$ insulation produced by sol-gel method, J. Magn. Magn. Mater. 322 (2010) 3748-3754, https://doi.org/ 10.1016/j.jmmm.2010.07.032

[44] S. Dobák, J. Füzer, P. Kollár, M. Fáberová, R. Bureš, Interplay of domain walls and magnetization rotation on dynamic magnetization process in iron/polymer-matrix soft magnetic composites, J. Magn. Magn. Mater. 426 (2017) 320-327, https://doi. org/10.1016/j.jmmm.2016.11.084.

[45] B. Yang, Z.B. Wu, Z.Y. Zou, R.H. Yu, High-performance $\mathrm{Fe} / \mathrm{SiO}_{2}$ soft magnetic composites for low-loss and high-power applications, J. Phys. D Appl. Phys. 43 (2010) 365003, https://doi.org/10.1088/0022-3727/43/36/365003. 